\title{
SEGURANÇA NAS UNIVERSIDADES BRASILEIRAS: PERSPECTIVAS PÚBLICAS INSTITUCIONAIS COMPARADAS
}

\section{Christiane de Holanda Camilo Fernanda Matos Fernandes de Oliveira Jurubeba}

Resumo: Este artigo é uma apresentação dos resultados preliminares dos dados levantados no "Projeto de Pesquisa Violências, Conflitos e Crimes: Subsídios para a Formulação da Política de Segurança da UFG" realizado entre 2014-2015. O objetivo é analisar as políticas de prevenção à violência nas Universidades. A metodologia empregada foi uma pesquisa exploratória e documental pautando-se das informações públicas disponibilizadas nos sites institucionais. As cinco universidades pesquisadas foram: UFSC, USP, UFMT, UFMG e UNILA. Os resultados obtidos permitiram visualizar certa aproximação e divergência sobre as concepções de segurança nos campi, quanto ao registro estatístico e a presença da polícia militar na universidade.

Palavras-chave: Direitos Humanos, IES, Segurança, Conflito, Violência.

\section{SECURITY IN BRAZILIAN UNIVERSITIES: COMPARED PROSPECTS OF PUBLIC INSTITUTIONS}

Abstract: This article is a presentation of preliminary results of the data collected in the "Research Project Violence, Conflict and Crime: Subsidies for the Formulation of UFG Security Policy" held between 2014-2015. The objective is to analyze policies to prevent violence in universities. The methodology used was an exploratory and documental research and are based public information available on institutional websites. The five universities surveyed were: UFSC, USP, UFMT, UFMG and UNILA. The results allowed certain approximation and divergence on the concepts of security on campuses, as the statistical record and the presence of military police at the university.

Keywords: Human Rights, IES, Security, Conflict, Violence.

\section{Introdução}

O presente artigo é fruto de um projeto específico nascido no bojo do projeto de pesquisa "Violência, Risco e Tráfico de Drogas", coordenado pelo Núcleo de Estudos sobre Criminalidade, Violência e Justiça Criminal (NECRIVI) da FCS/UFG. Trata-se do projeto "Políticas de Prevenção à Violência em Campi Universitários: um estudo institucional em perspectiva comparada".

Esta pesquisa se propôs a comparar diferentes soluções e políticas adotadas por universidades públicas brasileiras quanto à questão da violência nos respectivos campi e entornos. A pergunta que se pretende responder expressa-se do seguinte modo: como se relacionam diferentes desenhos institucionais e políticas de prevenção ou controle da 
violência nas universidades públicas brasileiras?

Um diagnóstico deste vulto pressupõe o estabelecimento de termos e parâmetros que possibilitem a formulação de prognósticos mais confiáveis, além de descrições de cenários mais robustos.

A Constituição da República assegura, em seu artigo 207, autonomia didáticocientífica, administrativa e de gestão financeira e patrimonial às universidades. Em que pese a inocorrência de regulamentação desse dispositivo em sede de Lei Ordinária e tampouco de uma sedimentação jurisprudencial quanto aos contornos devidos à autonomia em questão, é certo que as diferentes universidades brasileiras ostentam culturas acadêmicas e organizacionais peculiares (BRASIL, 1988).

As universidades públicas, em especial, tendem a contar com modelos de composição dos respectivos órgãos de base, processos decisórios internos e práticas didáticopedagógicas frequentemente diferentes entre si. Desse cenário institucional, surgem diferentes respostas e abordagens para problemas comuns. No que concerne à prevenção da violência nos campi universitários, é bem provável que uma pluralidade de enfoques e abordagens entre diferentes instituições se verifique.

Este projeto se justifica precisamente em função da lacuna existente na ciência social brasileira, em particular nos estudos de criminologia e de sociologia da violência e sociologia das instituições, quanto aos levantamentos e comparações acima sugeridos. Não há, com efeito, uma base dados comparativa sobre taxas de crime e práticas violentas em diferentes campi do Brasil. Inexiste, igualmente, um estudo voltado à comparação ou mesmo à simples justaposição de políticas empreendidas por diferentes administrações universitárias quanto à temática da violência. Por fim, não há estudos sócio-científicos voltados à identificação das relações possíveis entre diferentes desenhos institucionais, processos decisórios e políticas de prevenção ou controle da violência nas universidades brasileiras.

Serão utilizadas fontes documentais disponíveis em repositórios públicos da internet. A metodologia empregada tomou como referência os diagnósticos realizados pelas instituições, os principais problemas recorrentes, assim como as estruturas montadas pelas instituições universitárias, pautando-se das informações públicas disponibilizadas nos sites institucionais, visto que o direito humano à segurança também é garantido por meio do acesso à informação, e a administração pública em qualquer esfera e finalidade de atuação deve assumir essa postura como parte de sua estrutura e política institucional. 
Adota-se a modalidade de pesquisa comparativa, centrada sobre as relações entre desenhos organizacionais-regimentais, processos decisórios internos de políticas para abordagem da violência adotando-se a seguinte sequência de termos para busca: políticas de prevenção à violência, violência, segurança, conflito, adotando-se uma sequência indutiva das situações que podem insurgir relacionadas ao tema da pesquisa e à segurança.

As cinco IES pesquisadas foram escolhidas por serem instituições de grande porte, dentre as mais antigas e mais recentes instituições superiores de ensino, destacando-se ainda o formato institucional diferenciado e as informações públicas noticiadas na mídia sobre a tríade conflito, segurança e violência. Assim chegou-se a quatro instituições federais de ensino e uma estadual, são elas: Universidade Federal de Santa Catarina (UFSC), Universidade de São Paulo (USP), Universidade Federal de Mato Grosso (UFMT), Universidade Federal de Minas Gerais (UFMG) e Universidade da Integração LatinoAmericana (UNILA). Todas elas, renomadas instituições que devido ao seu porte, lidam diuturnamente com situações conflitivas.

As instituições foram pesquisadas a partir de seus sites oficiais em busca de documentos como estatutos, regimentos, normativas e notícias entre outras informações, de modo a identificar o encadeamento entre as seguintes variáveis: 1) Existência ou inexistência de uma política formal e abrangente para prevenção e controle da violência no campus e em seu entorno; 2) Presença ou não de policiamento militar ostensivo de modo rotineiro nas dependências da instituição; 3) Disponibilidade de dados em série sobre evolução da ocorrência de ilícitos penais nas dependências e no entorno do campus universitário.

A seguir, são apresentados os dados e impressões coletados para, na seção conclusiva, expor-se ideias e sugestões que podem ser extraídas a partir dos levantamentos empreendidos.

\section{1) Existência ou inexistência de uma política formal e abrangente para prevenção e controle da violência no campus e em seu entorno;}

UFSC - O Estatuto da Universidade Federal de Santa Catarina, Resolução no 65 de 1978, de 3 de novembro de 1978 é omisso quanto ao tema da prevenção segurança, violência e do conflito. Já o Regimento Geral, (Decreto-Lei no 464 de 11 de fevereiro de 1969), embora não contemple menção expressa ao assunto, estabelece no artigo 25 que compete ao "Conselho da Unidade" “[...] X. deliberar sobre providências preventivas, 
corretivas ou supressivas de atos de indisciplina coletiva (UFSC, 1969, 1978)".

A UFSC possui um "Departamento de Segurança Física e Patrimonial” (DESEG). Para a instituição, este é órgão é responsável pelo planejamento, execução, fiscalização, controle ou avaliação de projetos, além da realização de atividades em assistência, assessoria, fiscalização, perícia e suporte técnico-administrativos a projetos e atividades, da elaboração dos planos de segurança e normas reguladoras da segurança, da realização de operações preventivas contra acidentes, da execução de atividades de defesa patrimonial, das investigações e registro das anormalidades, registros de ocorrências de sinistros, desvios, furtos, roubos ou invasões, atuação em postos de segurança instalados nas entradas, portarias e vias de acesso e outras atividades de mesma natureza. Observa-se que a previsão protetiva, ou seja, o que a instituição objetiva proteção, de envolve dois itens, patrimônio e segurança física (UFSC, 2005).

A UFSC considera que a principal função da segurança na universidade é prevenir riscos e perigos, e que não se pode confundir segurança institucional com segurança patrimonial. A universidade trabalha na perspectiva da segurança institucional, que compreende envolver uma estrutura tridimensional, por envolver a segurança física (patrimonial - material e físico), a segurança estratégica (inteligência - proteção de patrimônio invisível, o ensino a pesquisa e a extensão) e a segurança especial (complementar - que está relacionada à segurança) (UFSC, 2014).

Os dados referentes às ocorrências registradas pelo DESEG podem até ser registrados e arquivados, todavia, não encontram-se disponibilizados no site da instituição.

USP - Na Universidade de São Paulo (USP) há certo tratamento do tema em sede de Regimento (Regimento Geral da Universidade de São Paulo. Resolução no 3.745, de 19 de outubro de 1988) e Estatuto (Estatuto da Universidade de São Paulo. Resolução no 3461, de 7 de outubro de 1988), como abaixo se pormenoriza.

O Estatuto da Universidade de São Paulo, após a alteração trazida pela Resolução $\mathrm{n}^{\circ}$ 6.061, dispôs, em seu artigo 34, XII, sobre a implementação da a Superintendência de Segurança, vinculada diretamente à Reitoria, com sede na Cidade Universitária.

O Regimento Geral, alterado pela Resolução n ${ }^{\circ}$ 5.493/2008 acrescentou a previsão no artigo 27-C da responsabilidade dos Conselhos Gestores dos Campi de "definir normas de segurança no campus”. Na sequência, por meio da Resolução no 6.062/2012, acrescentou-se à "Seção XIII-C - Da Superintendência de Segurança“, o artigo 38-C, onde lê-se que ela é 
responsável por “[...] planejar, implantar e manter todas as atividades de interesse comum relacionadas à segurança patrimonial e pessoal no âmbito da Universidade de São Paulo". O Regimento relembra ainda o vínculo da Segurança diretamente à Reitoria da USP no artigo 253 (USP, 2008, 2012b).

Em 24 de maio de 1984, o Reitor baixou a portaria GR 1.616, que criou a Central de Operações no Campus Butantã, e em seguida implantou o primeiro programa de Segurança para o Campus, cujas principais atividades eram operacionalizar o sistema viário do campus, fiscalizar e fazer a segurança das atividades nas áreas comuns por meio de rondas programadas e postos fixos, implantar serviços de apoio à manutenção e conservação das áreas comuns, bem como serviços de informação à comunidade, além de fiscalizar o uso e ocupação do solo por ambulantes (USP, 1984).

O Estatuto atual, criado em 1988, já consigna previsões sobre "segurança". Percebe-se que no decorrer do tempo foram aprimoradas as normativas da instituição. Em 1999, com o aumento de ocorrências no campus, a Reitoria criou o Conselho de Qualidade de Vida e Segurança da Cidade Universitária, com a expectativa de renovar a segurança na USP. À época o Jornal da USP descrevia a segurança como composta por 51 pessoas da Guarda Universitária, 341 pessoas de empresas privadas, 560 porteiros e vigias, um destacamento de 15 homens da Polícia Militar. Foi, igualmente, nesse período que se deu a instalação das primeiras câmeras de vídeo.

Em 2000, os agentes de segurança tornaram-se a Guarda Universitária. Em 2002, criou-se o Grupo de Estudos Técnicos de Segurança para registrar e catalogar os casos (contudo, GETS tornou-se inativo em 2012). Em 2011, foi assinado um Convênio com duração de cinco anos para a implementação do Policiamento Comunitário na USP em parceria com a Polícia Militar e, em 2012, o Departamento de Segurança, se tornou Superintendência de Segurança. Desde então, continuaram-se as alterações normativas tendentes à criação de órgãos e ao acréscimo de atribuições, o que não guardou significativa projeção fática ou material, ao tempo em que as alterações deontológicas e burocráticas não foram acompanhadas de medidas como contratação de guardas universitários ou significativo acréscimo no aporte de recursos para o tema (USP, 2000, 2002, 2011).

Mais recentemente, em maio de ano de 2014, verificou-se a instituição da Portaria GR n 6.550, que criou o Grupo de Trabalho sobre Segurança (GT-Segurança). A atribuição principal do GT era a avaliar a questão da segurança pessoal e patrimonial de interesse da 
comunidade da Universidade de São Paulo (USP, 2014). O GT culminou na elaboração de um relatório que previa política de fortalecimento da guarda universitária e combate aos crimes praticados pela própria comunidade, em especial as reiteradas práticas de violência contra mulheres em festas e ritos de passagens estudantis. Um trecho do documento previa como resultado esperado da nova política de segurança a consubstanciação do entendimeto de que

A USP não pode se calar diante de abusos e desrespeitos a direitos no interior de seus campi, em especial entre setores de sua própria comunidade. Demonstrações de que a Universidade está atenta e ativa nessa direção devem ser fartamente alardeadas (USP, 2014).

As normativas da USP, com a exceção do documento acima referido, cuja publicação coincidiu com a exoneração da superintendente da SPPU, não traduzem uma política de longo prazo sobre violência e segurança. Há, ao contrário, um somatório de medidas adotadas em períodos relativamente curtos e com alcances estreitos, sem a devida avaliação quanto aos efeitos provocados por políticas e práticas passadas ou um prognóstico controlado sobre o que se espera das novas alternativas. Não há, igualmente, fóruns abertos à comunidade para discussão e formulação de decisões sobre o tema.

UFMG - A Universidade Federal de Minas Gerais (UFMG) não possui em seu Estatuto (UFMG, 1999) ou Regimento (UFMG, 2012) qualquer previsão acerca da segurança ou violência nos campus.

A única referência à violência foi encontrada no Plano de Desenvolvimento Institucional para o período de 2013 -2017, em que se faz o resgate histórico do combate à violência pela UFMG na época da ditadura (UFMG, 2013).

O Plano de Desenvolvimento Institucional prevê o tratamento da segurança de forma patrimonializada, ou seja, trata de questões ligadas a sistemas de vigilância e monitoramento, e retoma que a Pró-Reitoria de Administração possui como objetivo o desenvolvimento de atividades-fim a partir de sua atuação em diferentes eixos. Um deles é a segurança, ao lado de limpeza e transporte (UFMG, 2013).

Quanto à melhoria da segurança, dos transportes e do trânsito, esse Plano estabelece que:

O intenso crescimento experimentado pela UFMG nos últimos anos, aliado 
aos impactos decorrentes dos pesados investimentos em obras de infraestrutura na região Norte de Belo Horizonte, vem resultando em pressão acentuada no Campus Pampulha, em termos de segurança, de transporte e de trânsito. Da mesma forma, o reinício da operação de grandes equipamentos urbanos em suas proximidades se, por um lado, enseja melhorias em termos de disponibilidade de transporte coletivo, por outro lado agudiza questões relativas a riscos, vulnerabilidade e pressão pelo uso do espaço universitário. Neste quadro insere-se o presente projeto (UFMG, 2013, p.137).

Este foi o introdutório utilizado pela Auditoria Geral, que elaborou o texto em que se pontuam, nos termos abaixo transcritos, os objetivos e metas da Universidade Federal de Minas Gerais para os próximos anos:

\subsubsection{OBJETIVO}

Melhorar as condições de segurança física e patrimonial na UFMG, bem como a circulação de pessoas e o trânsito de veículos, aí incluídas as possibilidades de estacionamento, no campus Pampulha.

\subsubsection{METAS}

1. Concluir a implantação do Plano Diretor de Segurança Universitária na UFMG, aprimorando-o com o uso de novas abordagens e ferramentas de análise.

\subsubsection{AÇÕES}

4. Melhorar as condições de segurança dos campi da UFMG, por meio do treinamento contínuo das equipes de vigilância; do emprego de técnicas de monitoramento eletrônico; da coleta de dados que permitam estabelecer indicadores de segurança adequados para orientar tanto os usuários desses ambientes, quanto a administração da Universidade. (UFMG, 2013, p. 137)

Considerações das quais consegue-se apreender que houve uma crescente preocupação com a segurança física dos usuários dos serviços e dependências da UFMG, e ainda, pontuou que a vigilância utilizada pela instituição precisa ser treinada e deve haver maior controle sobre a coleta e sistematização dos dados.

Observou-se, ainda, que atualmente a UFMG possui um "Departamento de Logística de Suprimento de Serviços Operacionais". Uma das atividades desse órgão é a "segurança e vigilância" nos campi e nos prédios da universidade.

Há, adicionalmente, na instituição, uma "Divisão de Segurança Universitária" ligada a esse Departamento. Suas responsabilidades estão assim dispostas:

Planejar, executar e controlar as atividades relativas à preservação do patrimônio público sob a responsabilidade da UFMG e da integridade física das pessoas que trabalham e circulam nos seus campi, como também orientar, acompanhar e fiscalizar a execução dessas atividades nos domínios das unidades e órgãos Setoriais da Instituição . 
Especificando melhor suas atribuições, a "Divisão de Segurança" determina a sua divisão em segurança predial e a segurança das áreas comuns, assim compreendidas:

Segurança predial Compreende os serviços que são prestados dentro dos prédios das unidades acadêmicas e administrativas e abrange as atividades executadas por vigias, porteiros e vigilantes terceirizados. A segurança predial é administrada pelas respectivas diretorias das unidades e órgãos, através de suas gerências administrativas e/ou secretarias e seções de serviços gerais, mas contam com o apoio técnico e logístico - orientação, acompanhamento e fiscalização - da DSU. As unidades e órgãos isolados e do campus Saúde contam também com o apoio técnico do Núcleo Avançado do DLO. Entretanto, a gestão dos contratos de prestação terceirizada de serviços bem como o monitoramento de alguns sistemas eletrônicos de alarmes e CFTVs (circuitos fechados de TVs) estão sob a responsabilidade da DSU. Segurança das áreas comuns Compreende os serviços que são prestados nas áreas comuns dos campi Pampulha e Saúde e abrange as atividades executadas por vigias, pela Polícia Militar de Minas Gerais (mediante convênio) e pelo corpo orgânico de vigilantes, pertencente à própria Instituição. A competência pela execução destes serviços é da Administração Central da Universidade, portanto, toda a gerência corre por conta da DSU. No campus Saúde, a coordenação do serviço é feita com o apoio do Núcleo Avançado do DLO e com a parceria da Comissão de Administração do campus Saúde.

UFMT - A Universidade Federal de Mato Grosso (UFMT), quer seja em seu Estatuto ou em seu Regimento, não apresenta previsão sobre questões de segurança. Todavia, a Resolução $\mathrm{n}^{\mathrm{o}} 8$ de 16 de fevereiro de 1976 instituiu nessa universidade a Guarda de Segurança da Fundação Universidade Federal de Mato Grosso (FUFMT) e estabeleceu que, hierarquicamente, ela está subornada à Vice-Reitoria para Assuntos Administrativos para a proteção patrimonial

Em 2002, foi aprovada a Resolução n 10 de 17 de abril de 2002, que autoriza o Reitor da UFMT, em conjunto com a Polícia Militar de Mato Grosso a elaborarem uma proposta de Polícia Comunitária para a UFMT.

Em 2010, com a Portaria GR no 309 de 12 de abril de 2010, implementou-se o Regulamento da Coordenação de segurança da Fundação Universidade Federal de Mato Grosso, que mesmo sendo recente permanece na perspectiva de proteção patrimonial e estabelece em seu artigo primeiro que "A Coordenação de Segurança destina-se ao cumprimento de encargos de proteção ao patrimônio da Fundação Universidade Federal de Mato Grosso, tarefas afins e excepcionalmente, a pessoa física.”. Porém, mais adiante, no artigo cinco, alínea “a”, o Regulamento estabelece que é missão específica adstrita à 
Coordenação de Segurança "Exercer a proteção do patrimônio da Fundação".

UNILA - A Universidade Federal da Integração Latino-Americana (UNILA) é a universidade mais recente no universo pesquisado. Foi criada em 2010, pela Lei $\mathrm{n}^{\circ} 12.189$, de 12 de janeiro deste ano.

Tanto o seu Estatuto quanto o Regimento Geral são omissos a respeito da questão de segurança. Todavia, no artigo terceiro do Regimento, observa-se que o Conselho Universitário (CONSUN) é o órgão máximo normativo e deliberativo para realizar o planejamento e o controle, dentre outros, patrimonial e disciplinar.

Porém, observa-se pelos Relatórios de Gestão de 2011, 2012 e 2013 que a Segurança é terceirizada.

O Plano de Desenvolvimento Institucional da UNILA de 2013-2017 dispõe que o "há profissionais terceirizados, que atuam em funções de segurança, recepção, limpeza, jardinagem e condução de veículos".

Observa-se ainda que a O Plano de Desenvolvimento Institucional prevê também a implantação de uma Comissão de Recepção, para atuar "No processo de recepção, serão respeitadas as diversidade dos estudantes de forma a resguardar, a segurança, e o bem-estar”.

\section{2) Presença ou não de policiamento militar ostensivo de modo rotineiro nas} dependências da instituição;

UFSC - Não há um convênio administrativo formalmente celebrado com a Polícia Militar. O próprio DESEG registra a ocorrência de delitos, conforme um boletim que segue modelo semelhante ao empregado por forças policiais. Em geral, diante de situações delitivas, orienta-se a vítima a registrar, além do boletim interno no DESEG/UFSC, uma segunda ocorrência no $5^{\circ}$ Distrito Policial, localizado nas proximidades do campus.

Há um trabalho de investigação, monitoramento e vigilância por parte do DESEG que, quando necessário, recorre às forças policiais. Não são comuns rondas ou presenças ostensivas de viaturas no campus.

USP - Na Portaria GR nº 1616, ou seja, desde 1984, como pode-se observar no artigo terceiro deste documento, a vigilância na USP acontece articulada com a Secretaria de Segurança Pública, por meio da atuação das Polícias Civil e Militar, quando, no campus, 
ocorrer qualquer "situação de natureza policial" (USP, 1984).

A USP é um caso peculiar em relação à presença da PM nas respectivas instalações. Primeiramente, tem-se que a Polícia Militar realiza rondas frequentes no campus Butantã e, não raramente, envolve-se em conflitos de ordem política próprios à instituição. Este é um traço comum à relação entre instituições universitárias públicas e Polícia Militar. A particularidade, contudo, reside no fato de que a Polícia Militar, por meio de oficiais egressos dos seus quadros, ocupa, com frequência, posições de destaque na SPPU, de tal ordem que, ao longo dos anos, a política de combate e redução da criminalidade na instituição se torna uma função da doutrina e da cultura próprias à Polícia Militar

UFMG - A UFMG celebra convênios com a Polícia Militar para a realização de policiamento ostensivo no campus. O Batalhão de Cavalaria assume a tarefa. Abaixo, tem-se o extrato de um desses convênios:

CONVÊNIO no 328/08 - PMMG e UFMG OBJETO: Cooperação mútua entre PMMG e UFMG visando manutenção de dois Postos de Policiamento Montado da PMMG, sendo a Sede do 3deg. Esquadrão no Campus Universitário da Pampulha e o PPM.2/3 ${ }^{\circ}$ Esquadrão no Museu de História Natural e Jardim Botânico, a fim de garantir o policiamento ostensivo e a preservação da ordem pública nas áreas mencionadas. VALOR: R \$81.144,00 por ano. DATA DE ASSINATURA: 12Mar2008

Nota-se, portanto, o aporte de recursos da União para polícia estadual, com vistas ao auxílio na manutenção de um esquadrão da cavalaria com atuação no campus.

UFMT - A UFMT, por meio da Resolução no 10 de 17 de abril de 2002, autorizou o início de um planejamento para implantação da Polícia Comunitária na UFMT.

Confira-se:

RESOLUÇÃO CONSUNI N. ${ }^{\circ}$ 15, DE 28 DE JUNHO DE 2002 CONSELHO UNIVERSITÁRIO DA UNIVERSIDADE FEDERAL DE MATO GROSSO, no uso de suas atribuições legais, e CONSIDERANDO a decisão da plenária em sessão realizada no dia 28 de junho de 2002;

R E S O L V E:

Artigo $1^{\circ}$. Autorizar a celebração de convênio entre a Universidade Federal de Mato Grosso e a Polícia Militar do Estado de Mato Grosso, com o objetivo de garantir o direito à segurança da comunidade universitária. 
Parágrafo Único. O convênio abrangerá, inicialmente, o campus de Cuiabá, podendo ser estendido aos demais campi e outras unidades externas, de acordo com avaliação de seus resultados, a ser realizada pela Administração Superior, acompanhada da Comissão referida no Artigo $3^{\circ}$ desta Resolução. Artigo $2^{\circ}$. O Convênio referido no Artigo $1^{\circ}$ obedecerá aos seguintes parâmetros: a) Garantia da autonomia universitária; b) Adoção de caráter experimental; c) Formação do efetivo em cidadania, ética, direitos humanos e a Universidade Pública.

Artigo $3^{\circ}$. Constituir uma Comissão do Conselho Universitário, composta pelos (as) conselheiros(as) Francisca Mercedes Teixeira, Ildomar Freitas de Oliveira e Miguel Rodrigues Netto, para acompanhar a implementação das ações previstas nos artigos anteriores.

Art. $4^{\circ}$. Esta Resolução entra em vigor nesta data, revogando-se as disposições em contrário.

A presença da PM no campus não parece cingir-se apenas à coibição de ilícitos penais, mas atém-se, igualmente, à atuação da força, em favor da administração universitária, nos conflitos de ordem política próprios à comunidade acadêmica. Em 2013, por exemplo, estudantes e advogados foram presos quando, acionada pela reitoria, a PM interrompeu um protesto em favor de moradias estudantis ${ }^{1}$.

UNILA- O Campus definitivo da UNILA ficará em área de segurança binacional. A instituição, ademais, define-se pelo caráter bilíngue e plurinacional das respectivas atividades. Destarte, a questão do policiamento militar no campus exorbita os assuntos de ordem interna à instituição.

\section{3) Disponibilidade de dados em série sobre evolução da ocorrência de ilícitos penais nas}

\section{dependências e no entorno do campus universitário.}

Na UFSC a Guarda Universitária mesmo que implementada a Superintendência de Segurança não existe a unificação das estatísticas ou a estatística separada por campus, só foi localizada a estatística do campus de Botucatu do último mês mas não menciona o número de casos (JORNAL DO CAMPUS, 2011).

Em termos estatísticos sobre a segurança no campus a UFMG, nota-se que entre 2003 e 2009, esses dados foram sistematizados, disponibilizados trienalmente pelo Departamento de Serviços Gerais, mais Especificamente a Divisão de Segurança Universitária, no site da instituição para consulta, sob o nome de "Relatório Resumido de Ocorrência", 
${ }^{1}$ Sobre o caso, a seguinte reportagem: <http://educacao.uol.com.br/noticias/2013/03/07/protesto-de-estudantesda-ufmt-termina-em-confronto-com-a-pm.htm>.

contudo, nenhum dado anterior ou posterior a esse período foi encontrado (UFMG, 2003, 2006, 2009).

Nem a UNILA nem a UFMT fazem disponibilização de dados sobre segurança.

\section{Considerações finais:}

Os casos apresentados permitem a obtenção das seguintes conjecturas:

1) Para a maioria das universidades pesquisadas, a segurança é uma questão essencialmente patrimonial, a pessoa ainda é secundária cenário.

2) Para as universidades em geral, a segurança é um tema terceirizado, ou para a segurança pública ou para a segurança privada.

3) A presença de policiamento militar ostensivo em dependências de campi universitários é uma medida que, tipicamente, não pode ser depurada de uma ingerência desse aparato em questões acadêmicas ou políticas próprias à dinâmica de instituições definidas, na forma do artigo 207 da Carta de 1988, por autonomia e, segundo o artigo 206, gestão democrática. Em todos os casos estudados, há relatos incursão da Polícia Militar em questões de ordem didática, científica e política próprias à dinâmica de conflitos, debates e interlocuções críticas de instituições acadêmicas.

4) Os problemas concernentes à violência e à criminalidade tendem a se exacerbar em contextos de ampliação nominal das vagas em universidades, sem a devida correspondência em âmbito orçamentário e de recursos humanos. A expansão da atividade noturna das universidades federais trouxe, igualmente, novos desafios em matéria de controle da criminalidade e da violência.

5) Instituições universitárias atuam, em geral, de modo reativo em matéria de violência e segurança. Ademais, não há espaços em que a matéria se submeta a planejamentos científicos, avaliações, elaborações de prognósticos e debates abertos à participação das comunidades acadêmicas. O tema, frequentemente, emerge quando ocorrem casos rumorosos e a tônica, em geral, concentra-se sobre os aspectos patrimonial e disciplinar. Violências de gênero, racismo, abusos de autoridade e assédios não costumam ser associados ao debates sobre o assunto. 
Em suma, verifica-se o seguinte padrão nas universidades públicas brasileiras:

a) Estatutos e regimentos, documentos normativos de maior fôlego quanto às balizas estratégicas e aos princípios norteadores das instituições, são, sempre, omissos quanto à questão da violência e da segurança. O tema, quando abordado, é classificado como ramo da gestão patrimonial, ladeado por matérias como limpeza e almoxarifado ou, adicionalmente, sob referências tácitas em disposições regimentais de ordem disciplinar. Ou seja, sob o aspecto da estática normativa, a segurança e a violência são um tema ausente.

b) Sob o prisma da dinâmica decisória, igualmente, o quadro supracitado se mantém. Em nenhuma das instituições perquiridas há fóruns permanentes, canais de diálogo e processos decisórios participativos ou porosos aos fluxos de debates ocorrentes em âmbito acadêmico dedicados à violência e à segurança. Trata-se, portanto, de assunto que, ao emergir, por ver-se cotidianamente alheio à processamentos democráticos, o faz de modo agonístico, sob a pressão de casos rumorosos e em ambiente de não gerenciável polarização. Não ocorrem, com efeito, políticas de prevenção inclusiva para a redução da violência, mas, tão somente, de reação coerciva.

c) Em que pese a frequente, ainda que informal, condução de um amplo debate sobre a presença de policiais militares em campi de universidades federais, nota-se a inocorrência de estudos que correlacionem a medida com a redução de ilícitos penais nas respectivas dependências. Ademais, o tema não é abordado à luz de memoriais sobre os dispêndios em vigilância, monitoramento e segurança. Igualmente negligenciado é o problema do não provimento, pela União, do cargo de vigilante universitário, previsto no anexo II da Lei ${ }^{\circ}$ 11.091/2005, com a redação atribuída pela Lei 11.233/2005. É possível formular-se a hipótese de que os clamores por policiamento militar nos campi de universidades federais revele a tentativa de terceirização de uma externalidade negativa, de modo a se respaldar cortes ou restrições orçamentárias em práticas como iluminação, instalação de alarmes, contratação de servidores públicos para o cargo de vigilantes, instituição de fóruns permanentes para debate e decisão sobre políticas de segurança etc.

6) Espaços vazios, como bosques e gramados, onde as instituições universitárias negligenciam-se quanto à realização permanente de ações de ensino, pesquisa ou extensão e quanto à gestão eficiente, por meio da promoção de atividades e da disponibilização de equipamentos e de tratamento urbanístico se revelam, usualmente, como especialmente vulneráveis em relação a delitos como tráfico de drogas e furtos. Casos como portarias isoladas na USP, bosque na UFSC, campo gramado na UFMG, de um lado; e bibliotecas com 
funcionamento 24 horas na UFMG, por outro lado; parecem indicar que a ocupação do espaço universitário é um relevante elemento na redução da violência.

7) Diante de episódios rumorosos sobre crimes ou práticas violentas em campi, instituições universitárias tendem a adotar medidas sob atípica celeridade decisional. Tais ações, entretanto, costumam ater-se a alterações normativas ou à criação de organismosburocráticos. Em geral, não dizem respeito a aporte de recursos, contratação de pessoas ou implementação de processos decisórios porosos às plurais demandas, impressões e visões ocorrentes entre discentes, docentes, técnicos administrativos, trabalhadores terceirizados e comunidade externa às instituições.

\section{Referências Bibliográficas:}

B.O.UFSC. Esta página tem o objetivo de expor relatos de ocorrências da UFSC e redondezas, além de pressionar os órgãos competentes para que tomem uma ação e dar indicar de como evitar situações traumáticas. 26 jul 2013. Disponível em: <HYPERLINK "https://www.facebook.com/B.O.UFSC"https://www.facebook.com/B.O.UFSC>. Acesso em: 15 out 2014 .

BRASIL. Lei $\mathrm{n}^{\mathrm{o}}$ 12.189. Dispõe sobre a criação da Universidade Federal da Integração Latino-Americana - UNILA e dá outras providências. Disponível em:

<http://www.planalto.gov.br/ccivil_03/_ato2007-2010/2010/lei/L12189.htm>. Acessado em: 12 out 2014.

FLYVJBERG, Bent. Making Social Science Matter: why social inquire failed and how it can succeed again. Cambridge: Cambridge University Press, 2011.

IRAHETA, Diego. Maconha na UFSC: reitoria repudia violência, 'truculência e intransigência' $d a$ polícia. 26 mar 2014. Disponível em: <http://www.brasilpost.com.br/2014/03/26/ufsc-maconha_n_5034619.html Acesso em: 15 out 2014.

MONDEK, Marino. Violência na UFSC: "são vagabundos”, disse a PM. 28 mar 2013. Blog Jornal Nota de Rodapé. Disponível em: <http://www.notaderodape.com.br/2013/03/violenciana-ufsc-sao-vagabundos-disse.html>. Acesso em: 15 out 2014. 
PARO, Denise. Estudante é encontrado morto em alojamento da UNILA. Gazeta do Povo, 14 mai 2012.

Disponível em: <http://www.gazetadopovo.com.br/vidaecidadania/conteudo.phtml?id=1254518>. Acessoem: 12 out 2014.

UNIVERSIDADE FEDERAL DA INTEGRAÇÃO LATINO-AMERICANA [UNILA]. Estatuto da UNILA. Disponível em: $<$ http://www.unila.edu.br/sites/default/files/files/ESTATUTO\%20UNILA\%20de\%2026\%20 DE\%2009(2)(1)(1).pdf>. Acessado em: 12 out 2014.

\section{UNIVERSIDADE FEDERAL DA INTEGRAÇÃO LATINO-AMERICANA [UNILA].} Estatuto da UNILA. Junho 2013. Disponível em: <HYPERLINK "http://www.unila.edu.br/sites/default/files/files/REGIMENTO\%20GERAL\%20UNILA\%20a provado\%20no\%20Conselho\%20em\%2007_06_2013(1).pdf"http://www.unila.edu.br/sites/de fault/files/files/REGIMENTO\%20GERAL\%20UNILA\%20aprovado\%20no\%20Conselho\%2 0em\%2007 06 2013(1).pdf>. Acessado em: 12 out 2014.

\section{UNIVERSIDADE FEDERAL DA INTEGRAÇÃO LATINO-AMERICANA [UNILA].} Plano de Desenvolvimento Institucional - PDI - 2013-2017. Disponível em: < httpHYPERLINK "http://www.unila.edu.br/sites/default/files/files/PDI\%20UNILA\%2020132017.pdf"http://www.unila.edu.br/sites/default/files/files/PDI\%20UNILA\%2020132017.pdf>. Acessado em: 12 out 2014.

UNIVERSIDADE FEDERAL DA INTEGRAÇÃO LATINO-AMERICANA [UNILA]. Relatório de Gestão do Exercício de 2011. Disponível em: $<$ http://www.unila.edu.br/sites/default/files/files/Relatorio\%20de\%20Gest\%C3\%A3o\%20UN ILA\%202011(1).pdf>. Acessado em: 12 out 2014.

UNIVERSIDADE FEDERAL DE MATO GROSSO [UFMT]. Lei $n^{o} 5.647$ de 10 de dezembro de 1970. Estatuto da Universidade Federal de Mato Grosso. Disponível em: < http://www.ufmt.br/sic/arquivos/08e48d44eee4f589dfc45ef0c2a833b3.pdf>. Acessado em: 10 out 2014. 
UNIVERSIDADE FEDERAL DE MATO GROSSO [UFMT]. Resolução $n^{\circ}$ 8/76. Organizar a Guarda de Segurança da Fundação Universidade Federal de Mato Grosso. Disponível em: <http://sistemas.ufmt.br/ufmt.resolucao/OpenResolucao.aspx?resolucaoUID=331\&ano=1976 \&tipoUID=1> . Acessado em: 10 out 2014.

UNIVERSIDADE FEDERAL DE MATO GROSSO [UFMT]. Apresentação da Agenda da PROAD. Disponível em: $<$ HYPERLINK "http://www.ufmt.br/proeg/arquivos/630ada40fa9c02e2886d56ae031f017d.pdf"http://www.uf mt.br/proeg/arquivos/630ada40fa9c02e2886d56ae031f017d.pdf > . Acessado em: 10 out 2014.

UNIVERSIDADE FEDERAL DE MATO GROSSO [UFMT]. Relatório Anual de Gestão 2010-2011. Disponível em: <HYPERLINK "http://www.ufmt.br/ufmt/site/userfiles/relatorios/relatoriogestao.pdf"http://www.ufmt.br/ufm t/site/userfiles/relatorios/relatoriogestao.pdf >. Acessado em: 10 out 2014.

UNIVERSIDADE FEDERAL DE MATO GROSSO [UFMT]. Portaria GR $n^{o} 309$ de 12 de abril de 2010. Regulamento da Coordenação de Segurança da Fundação Universidade Federal Mato Grosso. Disponível em: http://www.ufmt.br/ufmt/site/userfiles/boletins/e6d303684fefdb495326c016b8eb45da.pdfl>. Acessado em: 10 out 2014.

UNIVERSIDADE FEDERAL DE MATO GROSSO [UFMT]. Relatório Anual de Gestão 2010-2011. Disponível em: <HYPERLINK "http://www.ufmt.br/ufmt/site/userfiles/relatorios/relatoriogestao.pdf"http://www.ufmt.br/ufm t/site/userfiles/relatorios/relatoriogestao.pdf >. Acessado em: 10 out 2014.

UNIVERSIDADE FEDERAL DE MATO GROSSO [UFMT]. Resolução $n^{\circ} 10$ de 17 de abril de 2002. Autoria o Reitor da UFMT para juntamente com a Polícia Militar-MT, elaborarem a proposta de convênio, objetivando o apoio à segurança na UFMT pela Política Comunitária. Disponível em: $<$ http://sistemas.ufmt.br/ufmt.resolucao/OpenResolucao.aspx?resolucaoUID=5946\&ano=200 2\&tipoUID=3>. Acessado em: 10 out 2014. 
UNIVERSIDADE FEDERAL DE MINAS GERAIS [UFMG]. Resolução 04, de 4 de março de 1999. Novo Estatuto da Universidade Federal de Minas Gerais. Disponível em:< https://www2.ufmg.br/sods/Sods/Sobre-a-UFMG/Estatuto>. Acessado em: 10 out 2014.

UNIVERSIDADE FEDERAL DE MINAS GERAIS [UFMG]. Resolução complementar $n^{o} 3$ de 27 de novembro de 2012. Reedita, com alterações, a Resolução Complementar no 01/2010, de 16 de março de 2010, que aprovou o Regimento Geral da Universidade Federal de Minas Gerais. Disponível em:< HYPERLINK "https://www2.ufmg.br/sods/Sods/Sobre-a-UFMG/Regimento-

Geral"https://www2.ufmg.br/sods/Sods/Sobre-a-UFMG/Regimento-Geral>. Acessado em: 10 out 2014.

UNIVERSIDADE FEDERAL DE MINAS GERAIS [UFMG]. Plano de Desenvolvimento Institucional - 2013 - 2017. 19 abr 2013. Disponível em:< https://www.ufmg.br/conheca/pdi_ufmg.pdf >. Acessado em: 10 out 2014.

UNIVERSIDADE FEDERAL DE MINAS GERAIS [UFMG]. Divisão de Segurança Universitária. Disponível em: <https://www.ufmg.br/dlo/institucional_dsu.shtml>. Acessado em: 10 out 2014.

UNIVERSIDADE FEDERAL DE MINAS GERAIS [UFMG]. Divisão de Segurança Universitária - Relatório Resumido de Ocorrência - 2003 Disponível em: <HYPERLINK "https://www.ufmg.br/dlo/arquivo/DSU/estatistica_2003_2005.PDF"https://www.ufmg.br/dlo /arquivo/DSU/estatistica_2003_2005.PDF>. Acessado em: 10 out 2014.

UNIVERSIDADE FEDERAL DE MINAS GERAIS [UFMG]. Divisão de Segurança Universitária - Relatório Resumido de Ocorrência - 2003 Disponível em: <HYPERLINK "https://www.ufmg.br/dlo/arquivo/DSU/estatistica_2006_2008.PDF"https://www.ufmg.br/dlo /arquivo/DSU/estatistica_2006_2008.PDF>. Acessado em: 10 out 2014.

UNIVERSIDADE FEDERAL DE MINAS GERAIS [UFMG]. Divisão de Segurança Universitária - Relatório Resumido de Ocorrência - 2003 Disponível em: <HYPERLINK "https://www.ufmg.br/dlo/arquivo/DSU/estatistica_2009.PDF"https://www.ufmg.br/dlo/arqui 
vo/DSU/estatistica_2009.PDF>.Acessado em: 10 out 2014.

UNIVERSIDADE DE SÃO PAULO [USP]. Estatuto da Universidade de São Paulo. Resolução no 3461, de 7 de outubro de 1988. São Paulo, 07 out 1988.

UNIVERSIDADE DE SÃO PAULO [USP]. Regimento Geral da Universidade de São Paulo. Resolução $n^{o}$ 3745, de 19 de outubro de 1990. São Paulo, 19 out 1990.

UNIVERSIDADE DE SÃO PAULO [USP]. Mais qualidade de vida e segurança na USP. Jornal da USP. n. 380/99. São Paulo, 12 mar 1999.

UNIVERSIDADE DE SÃO PAULO [USP]. Regimento Geral da Universidade de São Paulo. Altera dispositivos do Regimento Geral da Universidade de São Paulo. Resolução $n^{\circ}$ 5493, de 2008. São Paulo, 16 dez 2008.

UNIVERSIDADE DE SÃO PAULO [USP]. USP assina convênio com Secretaria de Segurança Pública e Polícia Militar. Notícias USP. São Paulo, 09 set 2011.

UNIVERSIDADE DE SÃO PAULO [USP]. Dados da PM sobre queda na criminalidade são inconclusivos. Jornal do Campus. São Paulo. Edição no 389. 24 nov 2011.

UNIVERSIDADE DE SÃO PAULO [USP]. Regimento Geral da Universidade de São Paulo. Altera dispositivos do Estatuto da Universidade de São Paulo. Resolução no 6061, de 2012. São Paulo, 27 fev 2012a.

UNIVERSIDADE DE SÃO PAULO [USP]. Regimento Geral da Universidade de São Paulo. Altera dispositivos do Regimento Geral da Universidade de São Paulo. Resolução $n^{\circ}$ 6062, de 2012. São Paulo, 27 fev $2012 b$.

UNIVERSIDADE DE SÃO PAULO [USP]. Novo Superintendente de Segurança é especialista em gestão comunitária e direitos humanos. Boletim da Assessoria de Imprensa da Reitoria. no 57, São Paulo, 29 mar 2012c. 
UNIVERSIDADE DE SÃO PAULO [USP]. Portaria GR $n^{\circ}$ 6550, de 13 de maio de 2014. Dispõe sobre a criação de Grupo de Trabalho sobre Segurança (GT - Segurança).São Paulo 13 mai 2014.

UNIVERSIDADE FEDERAL DE SANTA CATARINA [UFSC]. Estatuto da Universidade Federal de Santa Catarina. Portaria ${ }^{\circ}$ 56, Santa Catarina, $1^{\circ}$ de fevereiro de 1982.

UNIVERSIDADE FEDERAL DE SANTA CATARINA [UFSC]. Regimento Geral da Universidade Federal de Santa Catarina. Decreto-Lei no 464, Santa Catarina, 11 de fevereiro de 1969.

UNIVERSIDADE FEDERAL DE SANTA CATARINA [UFSC]. Lei n ${ }^{\circ} 11.091 / 2005$. Santa Catarina. 2005.

UNIVERSIDADE FEDERAL DE SANTA CATARINA [UFSC]. Lei no 5.824/2006. Santa Catarina. 2006.

UNIVERSIDADE FEDERAL DE SANTA CATARINA [UFSC]. Ofício Circular n 15/2005. Santa Catarina. 2005.

UNIVERSIDADE FEDERAL DE SANTA CATARINA [UFSC]. Decreto $\mathrm{n}^{\circ}$ 5.824/2006. Santa Catarina. 2006.

UNIVERSIDADE FEDERAL DE SANTA CATARINA [UFSC]. Departamento de Segurança Física e Patrimonial. Fundamentação legal da área de segurança. Disponível em: < HYPERLINK "http://seguranca.ufsc.br/fundamentacao-legal-na-area-deseguranca/"http://seguranca.ufsc.br/fundamentacao-legal-na-area-de-seguranca/> . Acesso em: 15 out 2014. 